Retraction

\title{
Retracted: Subclinical Hypothyroidism and Its Association with Increased Cardiovascular Mortality
}

\author{
Cardiology Research and Practice
}

Correspondence should be addressed to Cardiology Research and Practice; crp@hindawi.com

Received 14 November 2017; Accepted 14 November 2017; Published 14 January 2018

Copyright (c) 2018 Cardiology Research and Practice. This is an open access article distributed under the Creative Commons Attribution License, which permits unrestricted use, distribution, and reproduction in any medium, provided the original work is properly cited.

Cardiology Research and Practice has retracted the article titled "Subclinical Hypothyroidism and Its Association with Increased Cardiovascular Mortality" [1]. The article was previously published as "Hassan, A., Altamirano-Ufion, A., Zulfiqar, B., Boddu, P., Sub-Clinical Hypothyroidism and Its Association with Increased Cardiovascular Mortality: Call for Action. Cardiology Research, North America, 8, May 2017." The authors appear to have inadvertently mixed up the two journals.

\section{References}

[1] A. A. Ufion, B. Zulfiqar, A. Hassan, R. Habibi, and P. Boddu, "Subclinical hypothyroidism and its association with increased cardiovascular mortality," Cardiology Research and Practice, vol. 2017, Article ID 7539735, 5 pages, 2017. 


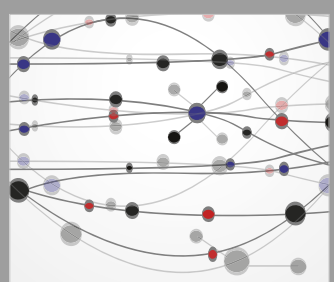

The Scientific World Journal
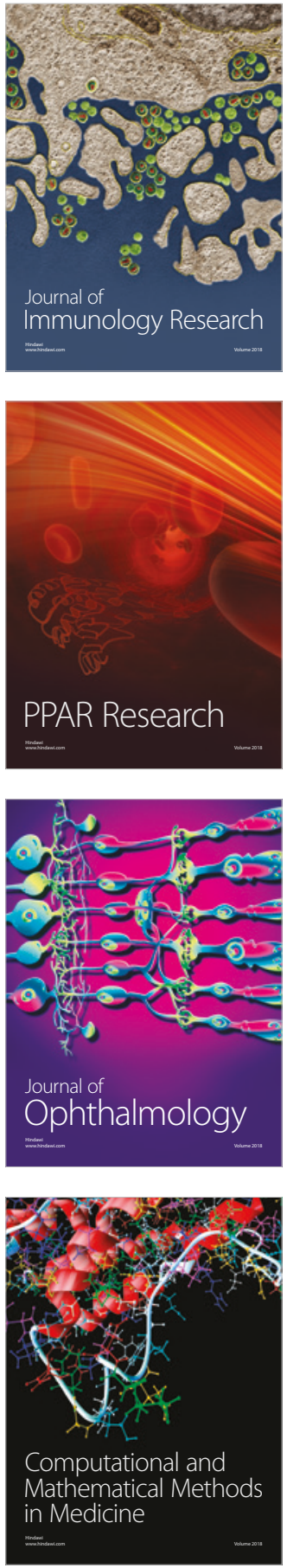

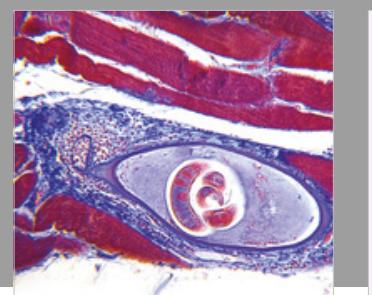

Gastroenterology Research and Practice

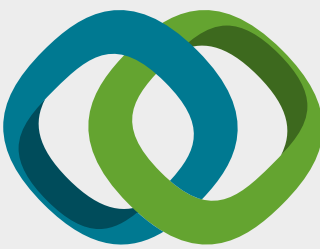

\section{Hindawi}

Submit your manuscripts at

www.hindawi.com
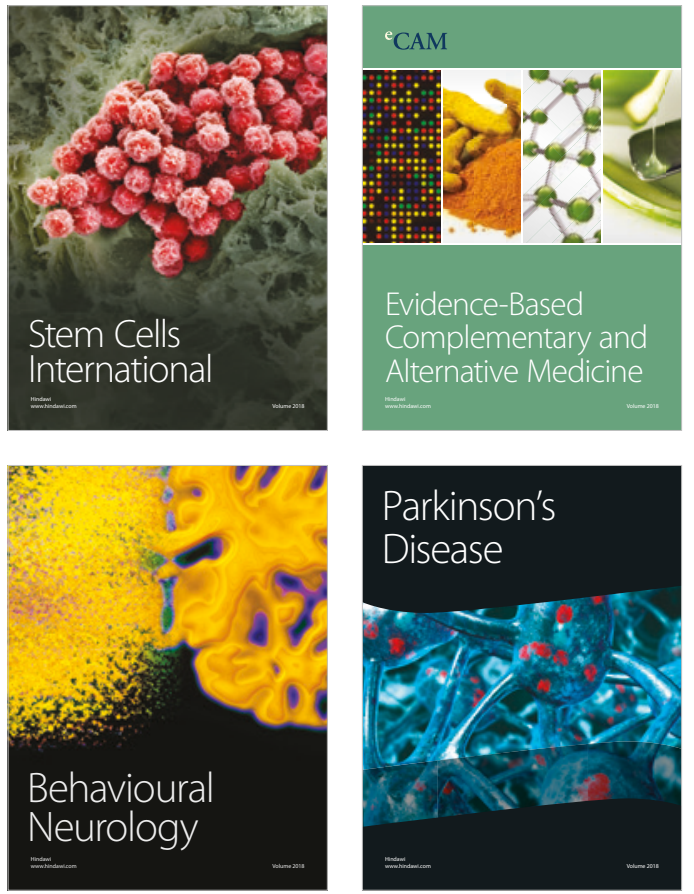

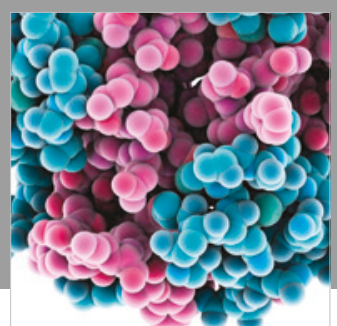

ournal of

Diabetes Research

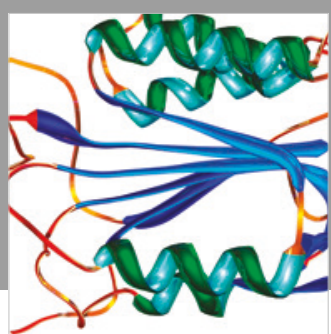

Disease Markers
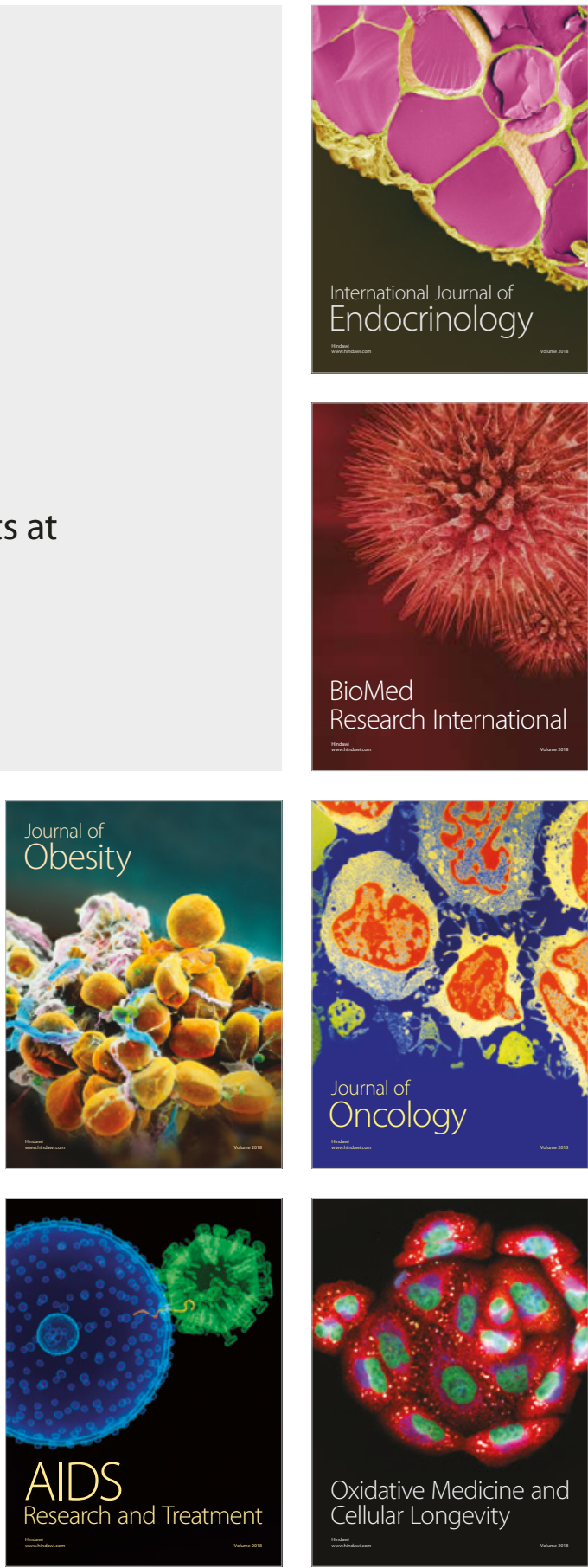